Opinion

\title{
External Penile Prosthesis that can be Easily made in a Few Minutes
}

\author{
Mingguang Yi* \\ Retired Electronics Engineer, Australia
}

*Corresponding author: Mingguang Yi, Retired electronics Engineer, 12 Marwood Ave, Truganina, VIC, 3029, Australia.

To Cite This Article: Mingguang Yi. External Penile Prosthesis that can be Easily made in a Few Minutes. Am J Biomed Sci \& Res. 2021 - 14(1). AJBSR.MS.ID.001950. DOI: 10.34297/AJBSR.2021.14.001950.

Received: 眥 August 16, 2021; Published: 制 August 30, 2021

\section{Abstract}

This article proposes a simple external penile prosthesis called an erection band, which can be easily made in a few minutes.

Keywords: Erectile Dysfunction; External Penile Prosthesis

\section{Introduction}

As a potential option for the treatment of erectile dysfunction, external penile prosthesis (EPP) has received a lot of attention in recent years [1]. However, so far, no EPP has been widely used. The existing hard EPP can cause vaginal foreign body sensation, so most women do not accept it [2]. In order to improve the overall satisfaction of women, the author recently proposed a new type of flexible band EPP [3]. But it is too thick and may fall off during intercourse. This article introduces a simpler, thinner and more

reliable band EPP, called an erection band, which consists of only a strip of white cardboard pasted on medical silicone tape or strapping, as shown in (Figure 1). The width of the paper strip is generally $4-6 \mathrm{~cm}$ and the length is $12-14 \mathrm{~cm}$. The erection band is very convenient to use. Just stick it and wrap it tightly on the shaft of the penis, as shown in Figure 1(d), and wear a condom to prevent the paper strip from getting wet. The only problem is that the pubic hair may be stuck. To avoid the trouble caused by pubic hair, it is best to cut it short or shave it off. (a)

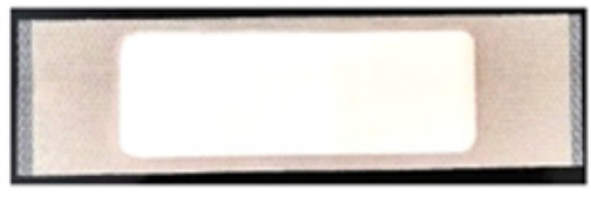

(c)

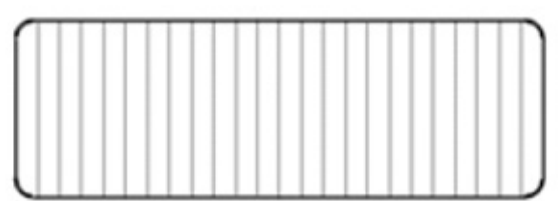

(b)

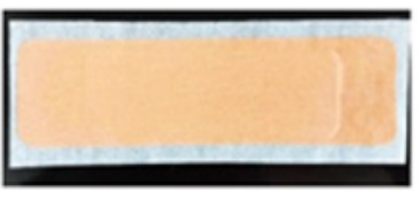

(d)

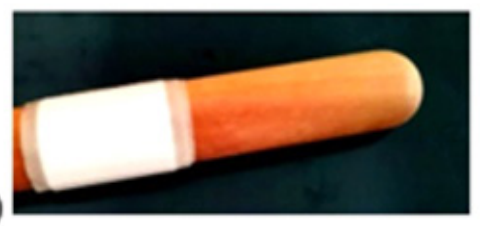

Figure 1: Erection Band Paper size: $4 \mathrm{~cm} \times 12 \mathrm{~cm}$

(a) Based on silicone tape. (b) Based on strapping tape. (c) A strip of paper with parallel creases. (d) Stick and wrap around the penis. 
The thickness of the erection band is less than $1 \mathrm{~mm}$. However, due to the use of paper strips, the carrying capacity is strong. The actual test shows that the paper strip of $300 \mathrm{gsm}$ can bear a weight of more than $5 \mathrm{~kg}$ when rolled up. The erection band obviously has good size adaptability. No need to customize for individual patients. In fact, the paper strip length of $12-14 \mathrm{~cm}$ is suitable for all patients whose penis diameter is less than $40 \mathrm{~mm}$. The production of erection bands is very easy. In fact, it only takes a few minutes. But $300 \mathrm{gsm}$ thick paper may be a bit stiff. In order to make it more flexible, it is best to prepare paper strips with parallel creases,. as shown in Figure 1(c). Since it is easy for doctors to DIY erection bands, the author hopes that this article will facilitate clinical trials of this kind of erection bands. The author also believes that the erection band will be accepted by most patients and their partners.

\section{Acknowledgement}

This research received no specific grant from any funding agency in the public, commercial, or not-for-profit sectors.

\section{Disclosure}

The author declares no conflict of interest in preparing this article. This study is the author's independent research. There is no any interest to disclose.

\section{References}

1. Wassersug R, Wibowo E (2017) Non-pharmacological and non-surgical strategies to promote sexual recovery for men with erectile dysfunction. Transl Androl Urol 6(Suppl 5): 776-794.

2. Mingguang Yi (2019)An improved external penile support. AME Med J 4: 9 .

3. Mingguang Yi (2021) A Practical External Penile Prosthesis. Am J Biomed Sci \& Res 12(5): 489-490. 